\title{
Effectiveness of Gamification for Flood Emergency Planning in the Disaster Risk Reduction Area
}

\author{
https://doi.org/10.3991/ijep.v10i4.13145 \\ Rania Rizki Arinta, Suyoto ${ }^{\varpi}$, Andi W.R. Emanuel \\ Universitas Atma Jaya Yogyakarta, Yogyakarta, Indonesia \\ suyoto@staff.uajy.ac.id
}

\begin{abstract}
Natural disasters are something that is not easy to predict, and one of them is a flood. Disaster risk reduction is the concept of how people minimize accidents and victims affected by disasters. The objective of this study is to utilize gamification to increase user effectiveness and to give an explanation of disaster preparedness for residents who live in the rural area. Gamification design consisting of game mechanics and dynamic games can increase user interest in education. This research was conducted at the disaster preparedness participant school with 65 participants, along with 21 communities affected by the flood disaster. The evaluation results in the aspect of usefulness (UU) gets the highest average value of 4,1225 or $83.19 \%$ of respondents to agree (very satisfied). With the usefulness, along with ease of usefulness being the most upper aspect from USE evaluation will help to facilitate the learning process and the process of accessing information and learning material. The results showed that gamification could increase the effectiveness in terms of time by $89.77 \%$ of information and knowledge about disaster risk and disaster preparedness to the public.
\end{abstract}

Keywords - Gamification, natural disaster, flood

\section{$1 \quad$ Introduction}

Natural disasters are usually followed by fatal damage. The level of contamination has an impact on the level of natural disasters. If a natural disaster occurs, the effect will be affected by the community and the environment. The effect of environmental damage and the number of fatalities depends on residents to anticipate natural disasters. To predict future natural disasters, citizens must know to reduce deaths when natural disasters occur. Residents must be prepared and know what to do when natural disasters occur [4].

One of the natural disasters that often occurs is flooding. The frequency of floods in 2019, according to the "Badan Nasional Penanggulangan Bencana (BNPB)" or National Disaster Management Agency, floods have occurred 505 times out of a total of 1824. Based on these results, it can be shown that flooding is a disaster that often happens in Indonesia [5]. Three places in Indonesia were affected by the biggest disasters during the last four years of 2016 to 2019 from the regions of West Java, East Java, and Central Java. Victims affected by the floods in 2016 amounted to 2,916,688 fatalities 
and damaged as many as 33,4017 houses were inundated and could not be used anymore, along with the loss of 1137 educational facilities [6]. In 2019 992,423 fatalities had to be evacuated [7].

Disaster risk reduction is a concept of disaster risk reduction to analyze and reduce the causes of disasters. According to UNISDR (United Nations Office for Disaster Risk Reduction) states four types of Priorities for action to reduce the risk of natural disasters. The first is understanding the risk of natural disasters. The second is to strengthen natural disaster risk management to manage natural disaster risk. The third is a place to make an investment process in disaster risk reduction. Fourth is to increase disaster preparedness for effective responses [4].

One of the factors why there are many victims of natural disasters is not giving knowledge to residents about the program of flood disaster emergency planning. Some residents do not understand the protocol and the preparation that must be done before a disaster occurs. "Badan Penanggulangan Bencana Daerah (BPBD)" or Regional Disaster Management Agency has implemented a training program along with seminars on disaster planning. But could not provide the training to all residents because of the large number of residents and the lack of available BPBD staff. Therefore, many residents are not given education about the emergency planning process so that it can increase the number of disaster victims when a disaster occurs.

Implementing gamification can complete the solution to fulfilling the disaster planning process for residents who have never learned or know about disaster preparation training because to learn new topics sometimes residents are not interested in using gamification can increase learning interest so that residents are interested in this topic and can prepare itself if a disaster that happened

This research will design a prototype of an emergency planning application through 3 stages, namely mitigation, emergency response, and disaster response, by utilizing gamification elements. The use of gamification method because its primary purpose is to increase learning, motivation, involvement, and effectiveness.

Participation and motivation for learning about disaster hazards are essential factors to reduce the risk of natural disasters [8]. The use of gamification by utilizing two parts of game mechanics along with dynamic games. Along with using USE testing. By using 4 USE criteria, namely usefulness (UU), Ease of use (EU), Ease of learning (UL), and satisfaction (US) [9]. This research also compares the effectiveness of time and labor savings before using the application and after using the app during the training process.

\section{Related Work}

Citizens' readiness in natural disasters is an essential factor in disaster preparedness programs. As research by Johnson et al. On what's the plan stand states that one of the factors for success in a disaster preparedness program is that it must have an interest in the subject. One example of R. Hoffmann's research in the Philippines is to help citizens increase interest in the matter of disaster preparedness by implementing a family evacuation plan [10]. Besides the Philippines, other countries implementing the disaster pre- 
paredness concept program are China and Nepal. This program is applied in the research of Newnham et al. on the program for children aged 13 years to 19 to reduce the victims of children in natural disasters [11]. Fema (Federal Emergency Management Agency) proposes four types of stages for the emergency management process. There are four stages: 1) mitigation 2) preparedness 3) Response 4) Figure 1 shows the flow chart of the emergency management process.

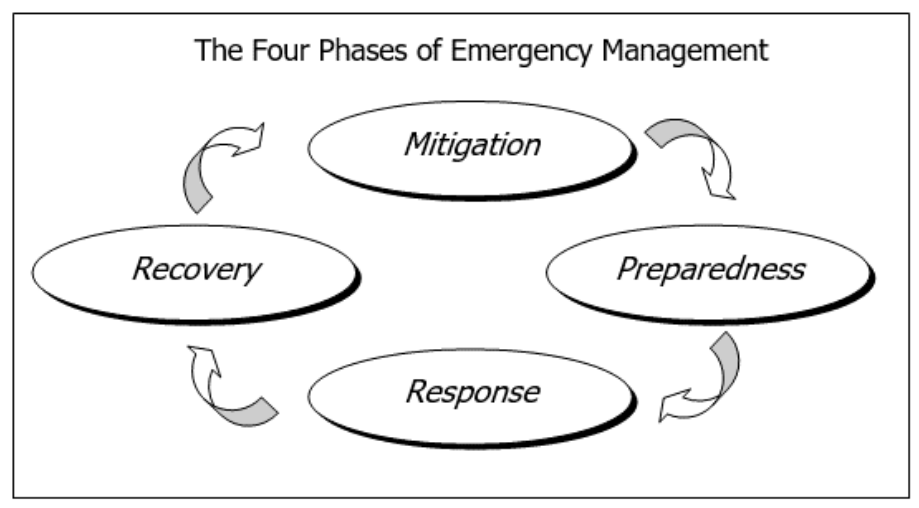

Fig. 1. Emergency management Fema [12].

Mitigation Stages are activities to prevent and reduce the possibility or reduce the effects of damage from natural disasters. Stages of preparedness are activities carried out before an emergency occurs. Activities carried out preparing evacuation plans and storing materials for evacuation, for example, food, water, and disaster equipment such as radios, batteries, lights, etc. The response stage is realizing the readiness plan at the preparedness stage. The recovery stage is the stage to return to typical situations after the disaster occurred [12].

Technology and facility use are essential factors in the success of the disaster preparedness program conducted by Johnson et al. [8]. One of the utilization of technology in disaster preparedness in the research of Barreto et al. is the severe use of games to anticipate disasters in elementary school children [13]. Another application in the study of Mitsuhara et al. Utilizes augmented reality for the evacuation training process [14]. According to Taehoon et al., The VR development technology made a significant impact on the education area [15]. Open simulator, an e-learning tool research conducted by Kohei, 2019, utilize avatar to find student week points throughout the learning proses [16]. Natural disasters that are not just applied for earthquakes, one of Schatz's researches, et al. discusses fire safety evacuation simulations utilizing augmented reality [17].

Gamification is a method used to increase motivation, interest, and user involvement [18]. The idea of gamification is to understand and choose which mechanics keep participants motivated and apply that concept to non-game environments[19].

In the background, it is explained that there is a lack of citizen involvement in the anticipation process. Also, along with a lack of motivation for disaster preparedness if 
the disaster has not yet occurred [8]. In the Meesters study, et al. stated that there is a relationship between gamification and disaster preparedness [20]. The domain of disaster preparedness can be applied to gamification according to the review of Koivisto et al., although there are still few studies that apply the topic [21]. To increase motivation and interest could be done by developing an educational innovation in the form of the game[22]. In research on crisis management and emergency training using gamification [2], the first element must divide the type of problem and share it into several sub-problems because it has limited time for decision making. After sharing the subproblem is to do the planning, the plan made must comply with the protocol that is appropriate to the situation and the role of the people involved. That is why it's essential to implement teamwork because we could divide the main tasks into smaller tasks and assign those smaller tasks into an individual. So each person plays a vital role in emergency training [23]. Furthermore, determining functions such as fire simulation research [1], in emergency training, a clear role must be established so that it has an individual task to solve several subproblems.

In the study of Mitsuhara et al., using gamification to increase visitors to the disaster risk museum. The result is an increase in visitors by utilizing gamification and providing virtual currency rewards that can be exchanged inside the museum. [3]. Meesters et al. conducted an emergency response study that had the results of using the concept of gamification in emergency response training to collect evaluation data regarding participant performance data [20].

Mokhtar et al. research discusses the process of anticipating flood disasters in the Malaysian case study comparing the features of the Malaysian Civil Defense Force (APM) [24]. The research of Hasegawa et al. discusses the decision-making skills of experienced volunteers by comparing the user based on the level of user awareness in the disaster [25]. Horita et al. utilize social, collaborative architecture to increase resistance to natural disasters by using five features, namely Communication Components, User Profiles Components, The Missions Components, Knowledge Components [26].

This research will be focusing on in this study will focus on emergency planning using three stages of mitigation, response, and recovery, as implemented by FEMA by applying mechanic and dynamic game designs. The previous research focused more on the collaborative method [1] [2], increasing visitors to the museum [3]. in this application is more focused on providing disaster response learning, especially for users who have never been given information about emergency planning but have experienced the disaster.

\section{$3 \quad$ Methodology}

In the methodology section, several steps must be done. Figure 2 shows the research flowchart. In figure 2 explains the contribution of the research. These contributions were marked with a red dotted box.in red. In this study, after collecting data about the process of disaster evacuation using surveys and direct interviews with BPBD staff. After that, analyze user needs and user specifications. 


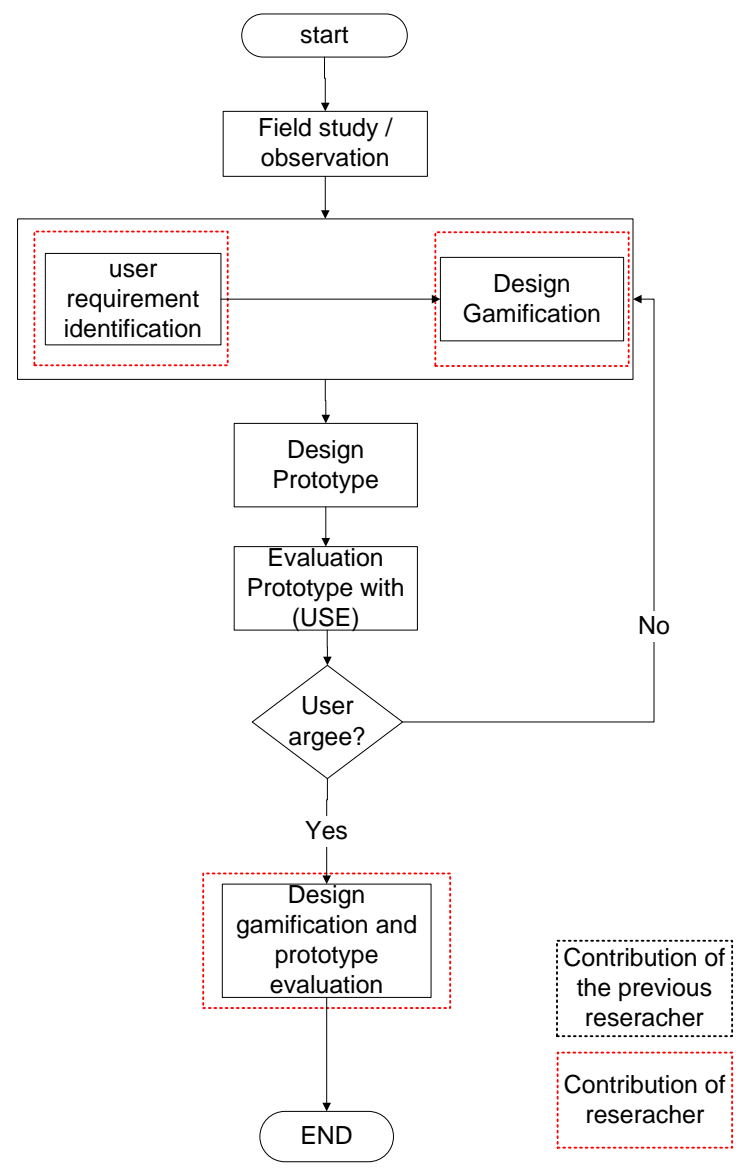

Fig. 2. Research flowchart

Table 1 shows the results that not all residents get practice, so with it, the application can provide training other than staff and students of disaster preparedness schools. At the response, stage staff must report incident reports and prepare equipment. But the team prioritizes priority groups, namely toddlers, pregnant women, and the elderly. Therefore, for those who are not from the priority group must understand how to save themselves and can go to the post of natural disasters and know the location of the job.

Table 1. User Specification

\begin{tabular}{|l|l|}
\hline \multicolumn{1}{|c|}{ Stages of emergency planning } & \multicolumn{1}{|c|}{ Facility activities provided to the community } \\
\hline Mitigation & $\begin{array}{l}\text { BPBD staff training and volunteer team. } \\
\text { Counseling in disaster preparedness Schools. }\end{array}$ \\
\hline Response & $\begin{array}{l}\text { Incident report A victim of top priority } \\
\text { Shelter }\end{array}$ \\
\hline Recovery & Assessment. \\
\hline
\end{tabular}


In this study, gamification will be divided into two parts, namely game mechanics and dynamic games. in active games and game mechanics, there are several elements, including levels, missions, quests, scores, virtual items.

Table 2. Gamification Design/Model Used [27]

\begin{tabular}{|l|l|}
\hline \multicolumn{1}{|c|}{ Game mechanics } & \multicolumn{1}{c|}{ Game dynamics } \\
\hline Points & Reward \\
\hline Level & Status \\
\hline Trophies, Badges, Achievements & Achievement \\
\hline
\end{tabular}

Table 2 shows several elements of gamification will be applied, which are game mechanics and dynamic games. The difference is Game Mechanics is an Input from the player that causes a set of responses from the system. The game rules. The game Dynamic Is What happens when the player's wants, goals, and intentions come in contact with the mechanics. The gameplay. Points can be exchanged into rewards provided in stores that consist of virtual items and reward items after completing levels and task walkthroughs. The level is in the task mission and walkthrough. After completing these levels, you can see the status of the processes of the players contained in the profile. Trophies, badges, achievements are obtained after completing a level to assess user performance on results that can be accessed on the profile. Badge gamification elements in educational systems may be used as game mechanics to animate non-game learning activities [28]. After that, the prototype is tested using a questionnaire using the USE (Usefulness, Satisfaction, and Ease of use) Questionnaire. It is an adaptation carried out by the research of Gao et al. [9]. By using the questioner method, they divided into four aspects of the evaluation of the prototype, which are usefulness, ease of use, ease of learning, satisfaction. The following USE questioner table has been adapted in Table 3 . 
Table 3. Questioner Use [9].

\begin{tabular}{|c|c|c|c|c|c|c|c|}
\hline \multirow{2}{*}{ No } & \multirow[t]{2}{*}{ Question } & \multirow[t]{2}{*}{ Labels } & \multicolumn{5}{|c|}{ scale } \\
\hline & & & 1 & 2 & 3 & 4 & 5 \\
\hline 1 & $\begin{array}{l}\text { The design of the application helped me understand } \\
\text { emergency planning for the flood disaster }\end{array}$ & UU1 & & & & & \\
\hline 2 & $\begin{array}{l}\text { The design of the application helped me understand } \\
\text { the stages and process of emergency planning for } \\
\text { floods }\end{array}$ & UU2 & & & & & \\
\hline 3 & $\begin{array}{l}\text { The application design can understand more quickly } \\
\text { understand the stages of emergency planning for flood } \\
\text { disasters }\end{array}$ & UU3 & & & & & \\
\hline 4 & $\begin{array}{l}\text { The application design can make it easier for me to } \\
\text { understand the stages of emergency planning for flood } \\
\text { disasters }\end{array}$ & UU4 & & & & & \\
\hline 5 & $\begin{array}{l}\text { It takes the smallest steps possible to complete the } \\
\text { gameplay and walkthrough provided in the design of } \\
\text { the application }\end{array}$ & UE1 & & & & & \\
\hline 6 & $\begin{array}{l}\text { The application design will help me learn faster to use } \\
\text { the application }\end{array}$ & UE2 & & & & & \\
\hline 7 & Flexible system design & UE3 & & & & & \\
\hline 8 & $\begin{array}{l}\text { The application design helps me learn faster to use the } \\
\text { application }\end{array}$ & UL1 & & & & & \\
\hline 9 & $\begin{array}{l}\text { The design of the application helped me to learn the } \\
\text { application easily }\end{array}$ & UL2 & & & & & \\
\hline 10 & I am satisfied with the design of the application & US1 & & & & & \\
\hline 11 & $\begin{array}{l}\text { The application design will work as I expect to learn } \\
\text { the application }\end{array}$ & US2 & & & & & \\
\hline 12 & The design of the application is very interesting & US3 & & & & & \\
\hline
\end{tabular}

Labels: UU=usefulness; UE=ease of use; UL=ease of learning; US=satisfaction

Table 3 shows a questioner use for scale one strongly disagrees, scale two disagree, scale three neutral, scale 4 agree, scale five strongly agree. There are 12 questions and divided into four aspects of usefulness, ease of use, ease of learning, satisfaction. The question has been tested for validity and reliability with a total of 36 correspondents. Here are the results of the reliability test using SPSS tools using Cronbach alpha in table 4.

Table 4. Reliability Statistics

\begin{tabular}{|c|c|c|}
\hline Cronbach's Alpha & Cronbach's Alpha Based on Standardized Items & N of Items \\
\hline .953 & .954 & 12 \\
\hline
\end{tabular}

Based on the above results that the Cronbach alpha value $>0.7$, it can be concluded that the questioner passed the reliability test.

\section{$4 \quad$ Result and Discussion}

At the field study stage, after interviewing and surveying BPBD staff that implementing gamification could attract users in the learning process of emergency planning. 
In the previous case to conduct the counseling process requires an expert team who must come to provide disaster threat learning and how to anticipate disasters to the community within three months with a time of learning for 90 minutes. Before conducting the outreach, the expert staff must do a training and selection process for three months. The extension process is very long and only covers a minimal number of people. Therefore, we use the gamification method so that we can include a higher number of people while also saving time and the number of staff. The following design results have been tested and validated by the BPBD, which includes the stages of mitigation, disaster response, and post-disaster.

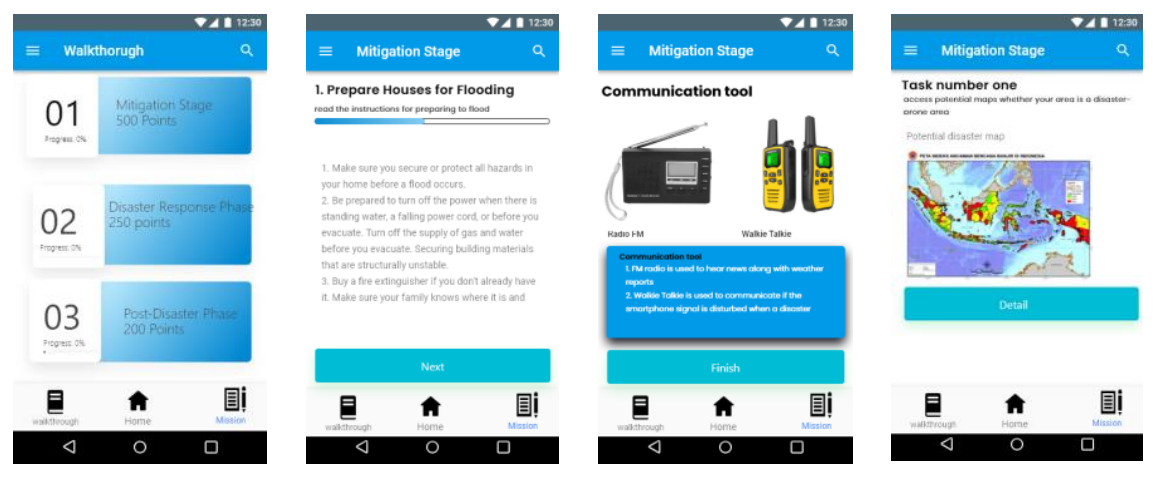

Fig. 3. Walkthrough menu for mitigation stage

Figure 3 shows the mitigation walkthrough menu is a menu done by the user before the disaster occurs, in which four tasks must be completed. The design came from the user requirement.

Based on the results of the user requirements of the mitigation phase, there is training and provision of material regarding the emergency planning process. In the task training, the user is given instructions on how and what methods should be prepared. Therefore, the design above is divided into smaller tasks rather than assigning significant and many responsibilities. So users can understand more easily. Thus, applying the design level and point gamification because each job has a different level of preparation. For functions that have more qualifications, such as mitigation, they will get more points because the mitigation stage is the most critical stage of the emergency planning process.

There are explanatory preparation menus before leaving the command post, a disaster kit preparation menu, and a map of potential emergency maps that provide red, yellow, and green status. Red indicates the state of the dangerous zone, and yellow indicates the standby zone. Green signifies a safe zone area. Next is for the disaster response phase menu in figure 4.

Figure 4 shows the walkthrough disaster response menu displays the list made by the user when a disaster occurs. Based on BPBD staff interview results and the user requirement. There are 112 services so that disaster victims can contact service 112 if 
they have a vulnerable family section. Vulnerable families are families that have members of infants, toddlers, pregnant women, the elderly, and the disabled. So that in the event of a disaster, the victim is a victim of top priority. The next task is the community must evacuate to a nearby command post.
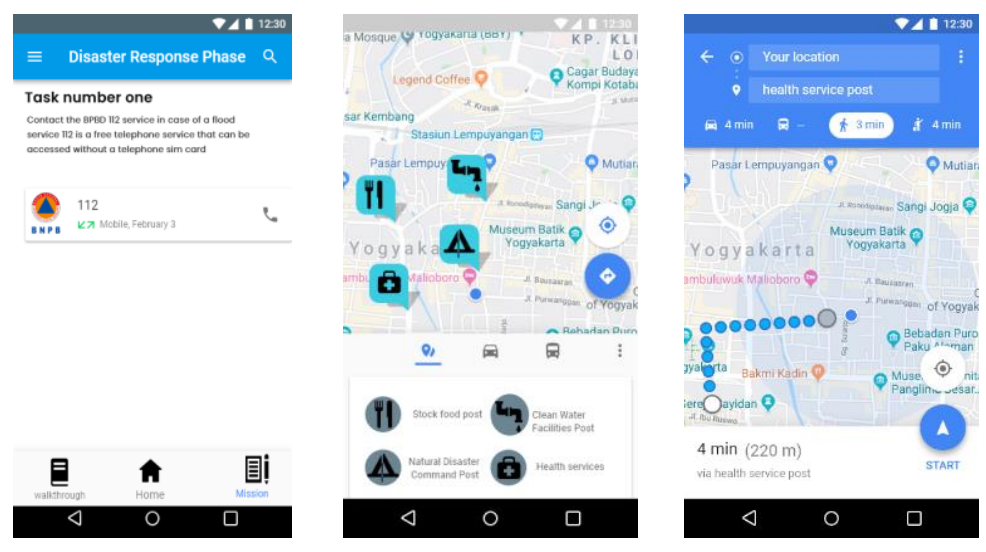

Fig. 4. Walkthrough menu for disaster response stage

Based on the results of interviews, the community staff experienced difficulties when heading to the position due to a lack of counseling processes regarding disaster risk, and did not know the map of the post to evacuate. Therefore, this application provides a map function so that people can see the nearest post from the house. In addition to easing the duties of BPBD staff and volunteers minimizing casualties when a disaster occurs.

Besides the walkthrough, there is a gameplay menu. In the gameplay, the process is divided into two parts of mitigation and disaster response - the following prototype gameplay in figure 5 .

After selecting the menu (result from figure 5), there are several levels. If, after completing a level, can unlock the next level. So, the user must unlock and complete tasks at each level to unlock them afterward. Next is the prototype gameplay after selecting the level in figure 6. 

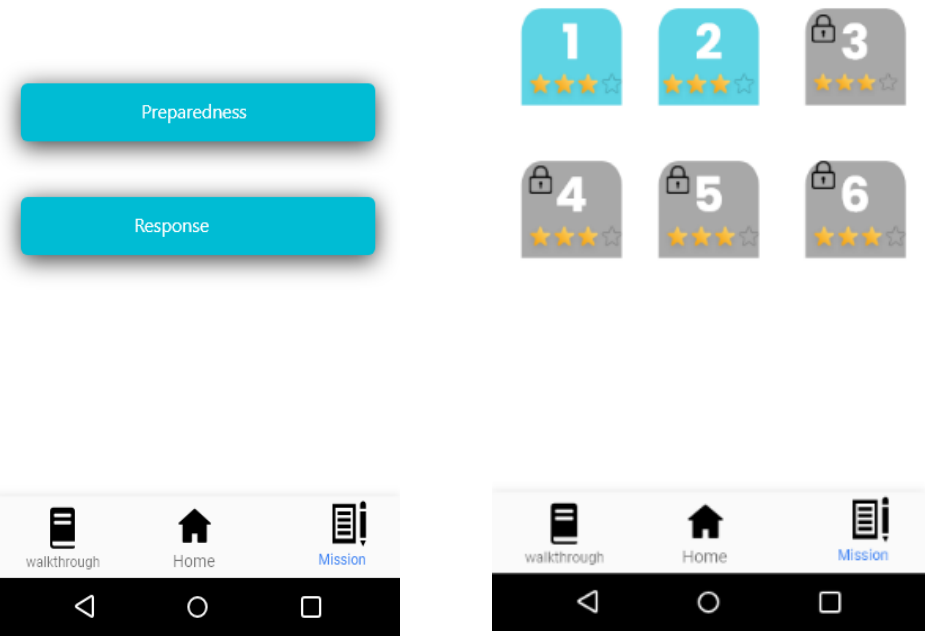

Fig. 5. Gameplay level selection
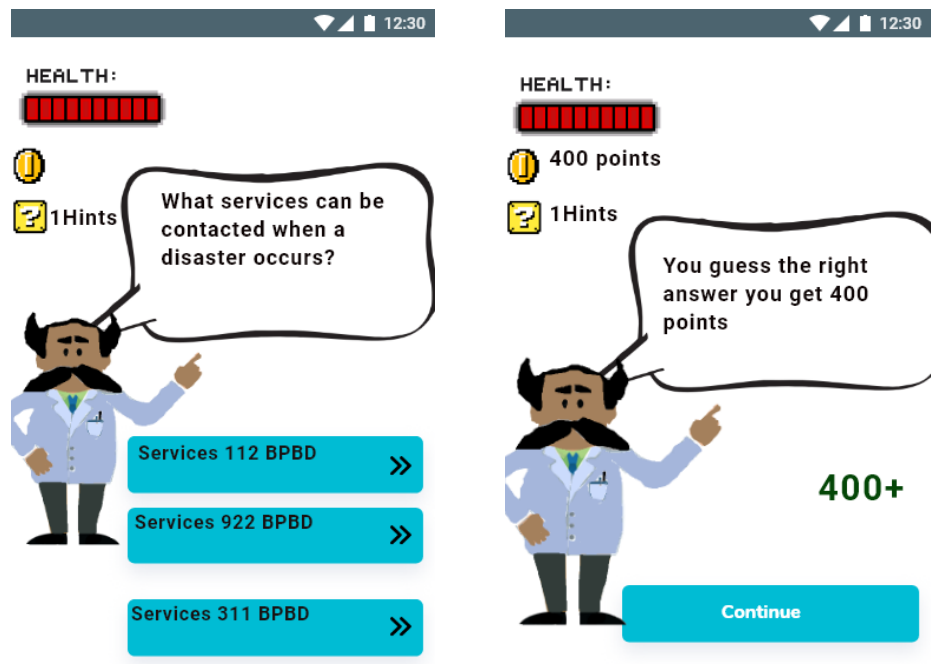

\section{HEALTH:}

\section{एणाए}

(9) 400 points

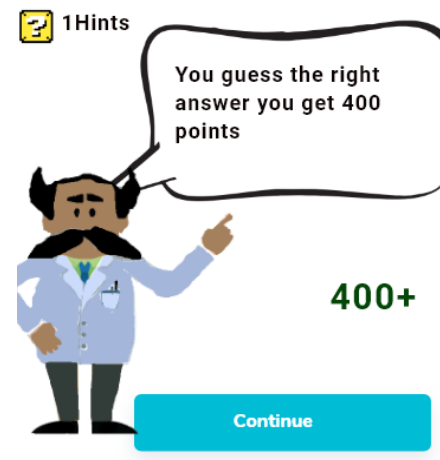

$\triangleleft$

○

Fig. 6. Gameplay mitigates and disaster response. 
In the gameplay menu, there are elements of hint, health, and coins (results from figure 6). There are 4-5 questions for level 2. Participants must answer these questions correctly. If the participant answers an incorrect answer, health will decrease, and if health runs out, the participant must repeat the level. The gameplay design is similarly based on the user requirement on the mitigation stage, which are BPBD staff training and volunteer team and Counseling in disaster preparedness Schools. When training and counseling before the user go to the simulation, they are given a question and answer sheet to see their level of understanding regarding emergency planning. That is why we choose the quiz element because it represents the real-life scenario before training and simulation.

After completing a level, get the point. These points can be exchanged at the store. Next is the Profile and Store menu in Figure 7.
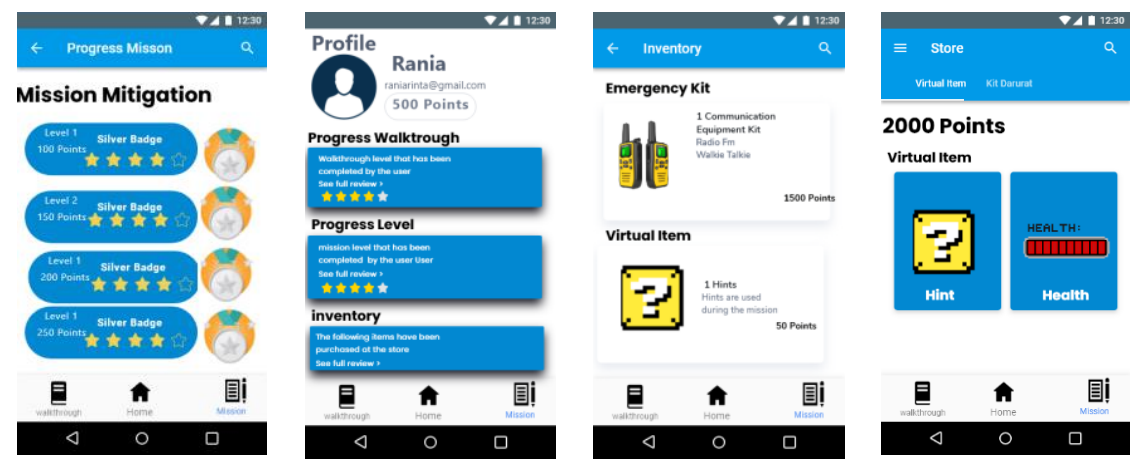

Fig. 7. Profile, inventory, store, and level of progress

Figure 7 shows the user's progress regarding the level that has been completed along with the inventory purchased at the store. So that users can monitor the performance of tasks and gameplay that has been played. In the store section, the user can exchange points for virtual items along with the original things. Virtual objects are used to help improve performance when playing games. While the original pieces can be exchanged so that the user does not need to prepare the tools at the mitigation stage. Each piece has a different point. Virtual item points have fewer points than the original item.

Based on the above design results, it can be concluded that the use of gamification design in the following table 5.

Table 5 shows the result of applying the design gamification. For elements of design points and levels are taken because they represent as when consoling and training at the mitigation stage. to evaluate the level of their understanding of emergency planning seen from the score test score, and their duties gave the test a different level of difficulty. The status element looks at their progress or performance regarding emergency planning. If the development is not sufficient, then the training process will be carried out, the same as the scenario during the training process in the field. 
Table 5. Result of gamification design

\begin{tabular}{|l|l|}
\hline \multicolumn{1}{|c|}{ Gamification Elements } & \multicolumn{1}{c|}{ Application design } \\
\hline Points & $\begin{array}{l}\text { Obtained after completing the task walkthrough } \\
\text { Obtained after completing the mission gameplay task }\end{array}$ \\
\hline Level & $\begin{array}{l}\text { Level levels applied to gameplay tasks are provided levels 1-6 } \\
\text { Level levels are applied to the task walkthrough stages of mitigation, disaster } \\
\text { response, and post-disaster }\end{array}$ \\
\hline Rewards & $\begin{array}{l}\text { Virtual items that can help complete the gameplay quiz } \\
\text { Original items that can be exchanged to facilitate the disaster mitigation phase }\end{array}$ \\
\hline Status & $\begin{array}{l}\text { Performance and progress status on the gameplay quiz on the profile } \\
\text { Performance and progress status on the walkthrough of the profile }\end{array}$ \\
\hline
\end{tabular}

The prototype process testing is using USE, which consists of 12 questions. This test was carried out with 65 participants coming from disaster preparedness schools along with 21 from surveys of ordinary people who had experienced and were affected by the flood disaster.

Table 6 indicates that the most common answers in Usefulness were agreed and strongly agree. The total participants that answer are recognized and strongly agree, a total of $84 \%$, and the rest of $16 \%$ answers neutral that the application is useful. That is why the total average is 4.122 because $84 \%$ of people agree and strongly agree that the apps are beneficial.

For the ease of use aspect, it is only $68 \%$ of participants agree and strongly agree that the application was easy to use the rest of $32 \%$ of the participants' responses neutral to the question. Mainly the problem ease of use number 3, which discusses the flexibility of the design.

Table 6. Result using USE

\begin{tabular}{|l|c|c|}
\hline \multicolumn{1}{|c|}{ Variable } & Mean score & Scale \\
\hline UU (usefulness) & 4.12216 & $82.4425 \%$ (very good) \\
\hline UE (ease of use) & 4.03788 & $80.7533 \%$ (good) \\
\hline UL (ease of learning) & 4.09091 & $81.815 \%$ (very good) \\
\hline US (satisfaction) & 4.03788 & $80.75 \%$ (good) \\
\hline
\end{tabular}

For the ease of the learning aspect, $84 \%$ of participants agree and strongly agree that the design is easy to learn, while the other $5 \%$ disagree that the design is not easy to learn. For the rest of the $12 \%$ of participants feels neutral about the ease of learning aspect. That is why the total average score is 4.09091 because participants answer is because participant results tend to agree and strongly disagree. Even though there is $5 \%$ of the participants didn't think the design is easy to learn.

For the satisfaction aspect, $75 \%$ of participants agree and strongly agree that the design works as they expect. But $20 \%$ of the participants feel neutral, and the rest of the $5 \%$ disagree that the design works as they expect. That is why the total average is 4.03788 because even though $75 \%$ agree that they satisfied with the design, there's a total of $5 \%$ of participants feel that they weren't satisfied with the application prototype design. 
That is why the lowest result was the US variables, which are the satisfaction aspect. Even though the US variables and the UE variables have the same average in the ease of use aspect, there aren't any participants that disagree with the ease of use aspect. But in the satisfaction aspect, there's a total of $5 \%$ of participants who disagree and feel that they weren't satisfied with the application prototype design.

It is based on table 6, that the highest value is in the aspect of usefulness. This aspect is the highest because, with the application, the participant feels helped and can learn the danger of disaster and preparation for disaster. Based on these results, if aspects of usefulness, along with high ease of usefulness, will facilitate the learning process and the process of accessing information and learning material. From previously unable to obtain material to be able to easily access the material and see the progress of learning performance using the application without having to wait for staff to provide the material. Before the apps, the community had to wait for training and outreach on disaster hazards and preparation for disasters from BPBD staff. With the participant, the apps can access information at any time without waiting for training and outreach schedules. Based on table 6, the lowest value is the satisfaction aspect of 4.03788. Application design given especially at the walkthrough stage is lack of animation that demonstrates the stages that must be done.

To prove the level of effectiveness judging from the level of time and labor by comparing the old process with after using the application. The following table 7 is the result of effectiveness based on time.

Table 7 shows for the counseling process time educating the danger of disaster to the community by explaining directly and coming directly to the location of the disaster preparedness school. The counseling time process at one meeting takes 90 minutes for one session, which is assisted by 200 people consisting of transportation, logistics, mitigation, and emergency response teams, whereas the application can save 70 minutes. With the apps, it can be accessed at any time without having to wait for the transportation, logistics, mitigation, and emergency response teams to provide counseling to the community.

At the counseling stage, the saved efficiency time rate was $89.7 \%$. Before the counseling stage to the community must provide a team of experts who come to give information and educate participants about flood disaster preparedness. Before giving information and teaching the participant about flood disaster preparation, the expert team was selected and trained in advance and took three months. 
Table 7. Effectiveness based on time

\begin{tabular}{|l|c|c|c|c|}
\hline \multicolumn{1}{|c|}{ Process Name } & $\begin{array}{c}\text { Processing time } \\
\text { with conventional }\end{array}$ & $\begin{array}{c}\text { Processing time with } \\
\text { the application }\end{array}$ & Difference & $\begin{array}{c}\text { The level of effi- } \\
\text { ciency saved }\end{array}$ \\
\hline $\begin{array}{l}\text { The process of providing } \\
\text { information and educat- } \\
\text { ing participants about } \\
\text { flood disaster prepared- } \\
\text { ness to the community }\end{array}$ & 90 minutes & 20 minutes 40 seconds & 70 minutes & $89.77 \%$ \\
\hline $\begin{array}{l}\text { The process of selecting a } \\
\text { team for training before } \\
\text { providing information } \\
\text { along with educating the } \\
\text { participant about flood } \\
\text { disaster preparation }\end{array}$ & Three months & - & - & $100 \%$ \\
\hline
\end{tabular}

Using the application is a much better option because the citizen doesn't have to wait for the training process and staff selection. For the counseling process, citizens must wait for the appropriate staff and require staff selection and selection so they cannot get information faster with the application they can more quickly obtain information. While using the apps does not need to select a team of experts to provide information and educate participants about flood disaster preparedness. With the application, the public can access it directly more easily. After evaluating the next time phase, evaluates at the labor stage.

Table 8 shows with the application of gamification does not need to require staff training for community outreach training and declared more effective because the training process involves selection time to select staff for the counseling process on natural disasters to the community directly. With the application, the city can access information about flood disasters without waiting for the team to come and provide information and educate participants about flood disaster preparedness. The counseling process requires 300 staff to provide information along with teaching the participant about flood disaster preparedness after staff training. In this study, at the time of the survey and testing, the application at the disaster preparedness school requires one person to explain and educate the participant about the flood disaster preparation through the prototype gamification application. After giving, giving information, and teaching the participant about flood disaster readiness regarding the respondent application can access the application through the link provided during the prototype testing.

Table 8. Effectiveness based on the labor

\begin{tabular}{|l|c|c|c|c|}
\hline \multicolumn{1}{|c|}{ Process Name } & $\begin{array}{c}\text { Number of } \\
\text { conventional } \\
\text { labor }\end{array}$ & $\begin{array}{c}\text { The number of } \\
\text { workers with appli- } \\
\text { cations }\end{array}$ & Difference & $\begin{array}{c}\text { The level of } \\
\text { efficiency } \\
\text { saved }\end{array}$ \\
\hline $\begin{array}{l}\text { The process of selecting a team for } \\
\text { training before providing information } \\
\text { along with educating the participant } \\
\text { about flood disaster preparation }\end{array}$ & 40 people & - & - & $100 \%$ \\
\hline $\begin{array}{l}\text { The process of providing information } \\
\text { and educating participants about flood } \\
\text { disaster preparedness to the commu- } \\
\text { nity }\end{array}$ & 200 people & One people & 199 people & $99.5 \%$ \\
\hline
\end{tabular}




\section{Conclusion}

The application can help the citizen to prepare for emergency planning without having to wait for BPBD staff to provide counseling and training. This information is difficult to obtain with the Citizen application, which can access it at any time without having to wait for BPBD staff and more residents who can access the apps.

The evaluation results the application usefulness (82.4425\%) along with ease of usefulness $(81.815 \%)$ is the highest aspect of the evaluation results (excellent scale) will facilitate the learning process and the process of accessing information and learning material. And therefore, We will have a better learning experience due to the accessibility of information about disaster preparation.

The counseling process saves time as much as $89.77 \%$ in one meeting. So the citizen could review the learning process by using the application rather than waiting for the next counseling process. Therefore, it is much more efficient.

\section{References}

[1] G. Rego, "Web-based micro-world simulation for emergency management training," Futur. Gener. Comput. Syst., vol. 17, no. 5, pp. 561-572, 2001. https://doi.org/10.1016/S0167739X(00)00039-X

[2] N. Capuano and R. King, "Knowledge-based assessment in serious games: An experience on emergency training," J. E-Learning Knowl. Soc., vol. 11, no. 3, pp. 117-132, 2015.

[3] H. Mitsuhara and M. Shishibori, "Virtual Currency as Gamification for Learning in a Disaster Museum to Increase the Number of Revisitors," 25th Int. Conf. Comput. Educ., pp. 746$754,2017$.

[4] United Nations Office for Disaster Risk Reduction, "Sendai Framework for Disaster Risk Reduction 2015 - 2030," Third UN World Conf. Disaster Risk Reduct. Sendai.

[5] BNPB, "Trends in Disasters of the Last 5 Years" (in Bahasa) 2018 [Online]. Available: https://bnpb.cloud/dibi/laporan4

[6] BNPB, "Number of Events (2016) FLOOD," (in Bahasa) 2016. [Online]. Available: http://bnpb.cloud/

[7] BNPB, "Number of Events (2019) FLOOD," (in Bahasa) 2019. [Online]. Available: http://bnpb.cloud/dibi/laporan5

[8] V. A. Johnson, K. R. Ronan, D. M. Johnston, and R. Peace, "Implementing disaster preparedness education in New Zealand primary schools," Disaster Prev. Manag., vol. 23, no. 4, pp. 370-380, 2014. https://doi.org/10.1108/DPM-09-2013-0151

[9] M. Gao, P. Kortum, and F. Oswald, "Psychometric Evaluation of the USE (Usefulness, Satisfaction, and Ease of use) Questionnaire for Reliability and Validity," Proc. Hum. Factors Ergon. Soc. Annu. Meet., vol. 62, no. 1, pp. 1414-1418, 2018. https://doi.org/10.117 7/1541931218621322

[10] R. Hoffmann and R. Muttarak, "Learn from the Past, Prepare for the Future: Impacts of Education and Experience on Disaster Preparedness in the Philippines and Thailand," World Dev., vol. 96, pp. 32-51, 2017. https://doi.org/10.1016/j.worlddev.2017.02.016

[11] E. A. Newnham et al., "Tailoring disaster risk reduction for adolescents: Qualitative perspectives from China and Nepal," Int. J. Disaster Risk Reduct., 2019. https://doi.org/10.1016/j.ijdrr.2018.12.020 
[12] Federal Emergency Management Agency, "Emergency Management in the United States Objectives What Are Disasters?" Federal Emergency Management Agency | Emergency Management Institute, pp. 1-16.

[13] P. António Cardoso Barreto, "Treme-treme -A serious game to teach children earthquake preparedness Information Systems and Computer Engineering Examination Committee," no. November, p. 86, 2014.

[14] J. Kawai, H. Mitsuhara, and M. Shishibori, "Game-based evacuation drill using augmented reality and head-mounted display," Interact. Technol. Smart Educ., vol. 13, no. 3, pp. 186201, 2016. https://doi.org/10.1108/ITSE-01-2016-0001

[15] T. Kim, C. Kim, H. Song, and M. Y. Sung, "Intuition, accuracy, and immersiveness analysis of 3D visualization methods for haptic virtual reality," Int. J. Adv. Comput. Sci. Appl., vol. 10, no. 11, pp. 30-37, 2019. https://doi.org/10.14569/IJACSA.2019.0101105

[16] K. Arai, "E-Learning System Using Mashup Based E-Learning Content Collection and an Attractive Avatar in Opensimulator," Int. J. Adv. Comput. Sci. Appl., vol. 10, no. 11, pp. 50-55, 2019. https://doi.org/10.14569/IJACSA.2019.0101107

[17] U. Rüppel and K. Schatz, "Designing a BIM-based serious game for fire safety evacuation simulations," Adv. Eng. Informatics, vol. 25, no. 4, pp. 600-611, 2011 https://doi.org/10.1016/j.aei.2011.08.001

[18] C. Wen, H. Hsien, and H. Huang, "A Survey of Gamification for Healthcare System," pp. 117-121, 2016. https://doi.org/10.1109/ICOT.2015.7498491

[19] K. Berkling and A. Zundel, "Change Management: Overcoming the Challenges of Introducing Self-Driven Learning," Int. J. Eng. Pedagog., vol. 5, no. 4, p. 38, 2015. https://doi.org/10.3991/ijep.v5i4.4945

[20] K. Meesters, "Gamification for Data Gathering in Emergency Response Exercises," no. January 2015.

[21] J. Koivisto and J. Hamari, "International Journal of Information Management The rise of motivational information systems : A review of gamification," Int. J. Inf. Manage., vol. 45, no. December 2018, pp. 191-210, 2019. https://doi.org/10.1016/j.ijinfomgt.2018.10.013

[22] N. Kristianti, S. Niwayan Purnawati, and Suyoto, "Virtual education with puzzle games for early childhood: A study of Indonesia," Int. J. Eng. Pedagog., vol. 8, no. 2, pp. 14-22, 2018. https://doi.org/10.3991/ijep.v8i2.7943

[23] N. Haferkamp and N. C. Krämer, "Disaster readiness through education - Training soft skills to crisis units by means of serious games in virtual environments," Lect. Notes Comput. Sci. (including Subser. Lect. Notes Artif. Intell. Lect. Notes Bioinformatics), vol. 6383 LNCS, pp. 506-511, 2010. https://doi.org/10.1007/978-3-642-16020-2_45

[24] N. Mokhtar, A. Ismail, and Z. Muda, "Preliminary Study : Flood Awareness Training Preparation Using Serious Games," J. Teknol. Mklm. dan Multimed. Asia-Pasifik, vol. 7, no. 2, pp. 13-26, 2018. https://doi.org/10.17576/apjitm-2018-0702(02)-02

[25] D. Wahyudin and S. Hasegawa, "Mobile Serious Game Design for Training Ethical Decision Making Skills of Inexperienced Disaster Volunteers," J. Inf. Syst. Educ., vol. 14, no. 1, pp. 28-41, 2016. https://doi.org/10.12937/ejsise.14.28

[26] F. Horita, L. Assis, and R. Castanhari, "A Gamification-based Social Collaborative Architecture to increase resilience against natural disasters," Agora.Icmc.Usp.Br, no. May, pp. 399-410, 2014.

[27] S. K. Huseyin Bicen, "Perceptions of Students for Gamification Approach: Kahoot as a Case Study," Int. J. Emerg. Technol. Learn., vol. 13, 2018. https://doi.org/10.3991 /ijet.v13i02.7467 
[28] R. Rughinis and S. Matei, "Badge Architectures as Tools for Sense-Making and Motivation in Engineering Education," Int. J. Eng. Pedagog., vol. 5, no. 4, p. 55, 2015. https://doi.org/10.3991/ijep.v5i4.4957

\section{$7 \quad$ Authors}

Rania Arinta is a master of informatics students at Universitas Atma Jaya Yogyakarta, Yogyakarta, Indonesia. Her research interest is in gamification and IoT.

Suyoto is a Professor in the Informatics at Universitas Atma Jaya Yogyakarta, Yogyakarta, Indonesia. His research interests are multimedia, computer graphics, visualization, mobile application, and artificial intelligence. Email: suyoto@staff.uajy.ac.id

Andi.W.R. Emanuel is a Full-time Lecturer (Associate Professor) at Universitas Atma Jaya Yogyakarta, Indonesia. His research interests in Software Engineering, Open Source Software, Open Source Communities, Software Metrics, and Software Quality.

Article submitted 2020-01-12. Resubmitted 2020-04-19. Final acceptance 2020-04-19. Final version published as submitted by the authors. 